\title{
Analysis of Uneven Settlement and Restoration Measures for One 220kV Transmission Tower
}

\author{
Mingjian Jian 1, 2, a, Guangcheng Zhang ${ }^{1,2, b}$, Duqing Zhang ${ }^{1,2}$, Guanglei Liu ${ }^{3}$ \\ and Zhongli Fan ${ }^{3}$ \\ ${ }^{1}$ State Grid Shandong Electric Power Research Institute, Jinan 250002, China \\ ${ }^{2}$ Shandong Electric Power Industry Boiler and Pressure Vessel Inspection Center Co. Ltd., Jinan \\ 250002, China \\ ${ }^{3}$ Guowang Sichuan Pengzhoushi Power Supply Limited Liability Company, Pengzhou 611930, \\ China \\ ajianmingjian2012@163.com, b13969093241@163.com
}

\begin{abstract}
Keywords: Transmission tower, Uneven Settlement, Finite element analysis, Reinforcing scheme. Abstract. One leaning tower of $220 \mathrm{kV}$ transmission line was taken as an example and a finite element model for the coupled tower-line system was established for investigating the effects of the uneven settlement on the transmission tower and line. The result shows that the bars of tower are compression-bending/tension-bending members which are under the combination action of bending moment and axial force. Von Mises equivalent stress value of Leg B is larger and the maximum stress value is 633MPa which is situated the root of tower leg, and it is larger than the yield strength of Q420 steel. Based on analyzing result, the reinforcing scheme was established.
\end{abstract}

\section{Introduction}

One $220 \mathrm{kV}$ transmission line goes over a goaf area of coal mine. Goaf area was located in 20 meters position on the north side of the Tower 32\# in this transmission line, 100 meters below the ground. Coal layer was about two meters thick, and coal mining operations had ended in December 2013. It was found that this tower suffered serious tilt on February 17, 2014. It caused the uneven settlement of the foundation of Tower 32\#, and ground wire sag between Tower 31\# and 32\# had shrunk. The tower body gave a lurch and larger additional stress came about correspondingly. Without immediate treatment the stability of foundation of the tower would be destroyed and that would lead to local or global failure of the tower body. Fig. 1 shows the serial numbers of the tower legs. About one meter long cracks appeared in 13 meters position on the south side of the Tower, as depicted in Fig. 2.

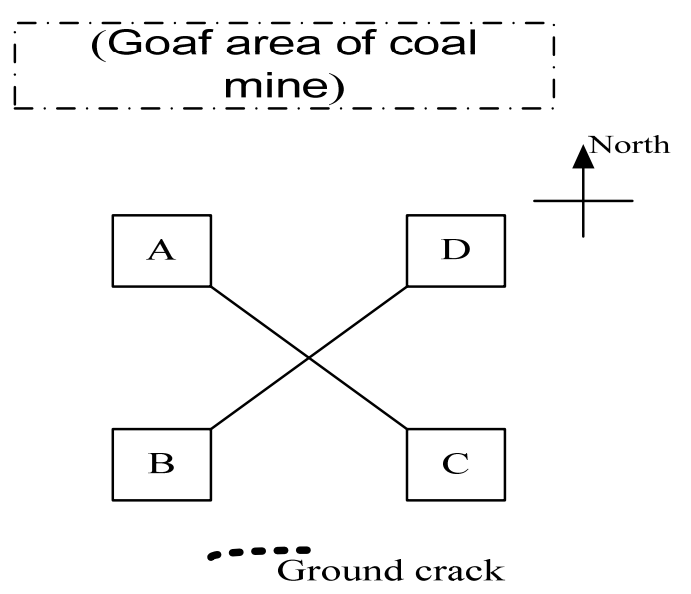

Fig. 1 Serial numbers of the tower legs

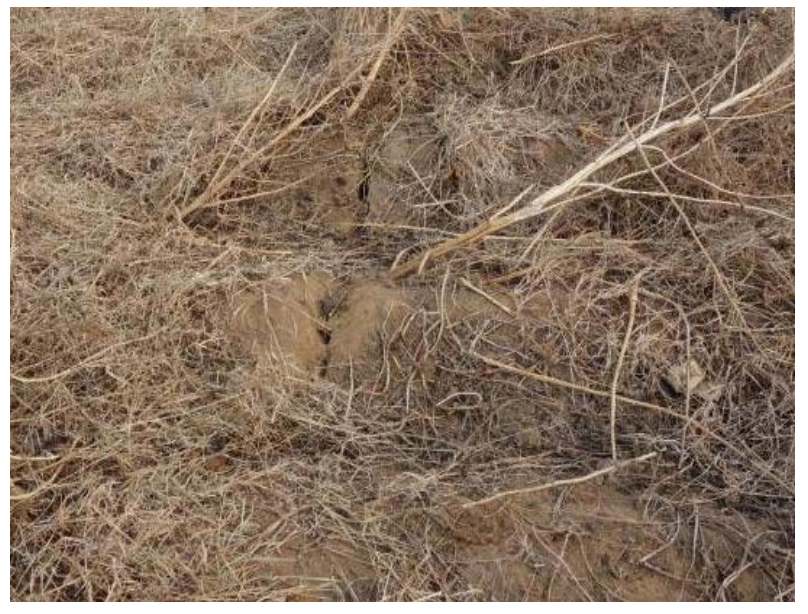

Fig. 2 About one meter long cracks

So far some foundations of transmission tower above goaf area of coal mine have taken place uneven settlement, slip, displacement and deformation, and most of them locate in Inner Mongolia Autonomous Region, Shanxi Province, Guizhou Province, Shaanxi Province and so on [1-4]. 
In this paper, the generally finite element analysis software ANSYS was used to establish the mechanics calculation models of the transmission tower, and research its structure characteristics. By analyzing the structural strength conditions of the towers in extreme operating conditions, the stress situation of each member was obtained, and the stress distribution of the tower was fixed. Based on analyzing result, the reinforcing scheme was established.

\section{Finite element model of the transmission tower}

Structure of the transmission tower. The transmission towers $32 \#$ is $220 \mathrm{kV}$ double circuit intermediate towers (SZ1552). The design is for the intermediate towers with nominal height of $27 \mathrm{~m}$, gross height of $43.523 \mathrm{~m}$, and root span of $8.466 \mathrm{~m}$. Both of the horizontal span and vertical span are $350 \mathrm{~m}$. Tower legs are connected by different specifications of Q420 angle steels, and the others are connected by Q345 and Q235 angle steels. The types of conductors and ground wires are $2 \times \mathrm{JL} / \mathrm{LB} 20 \mathrm{~A}-630 / 55$ and OPGW-120 respectively. The finite element model of tower is shown in Fig. 3.

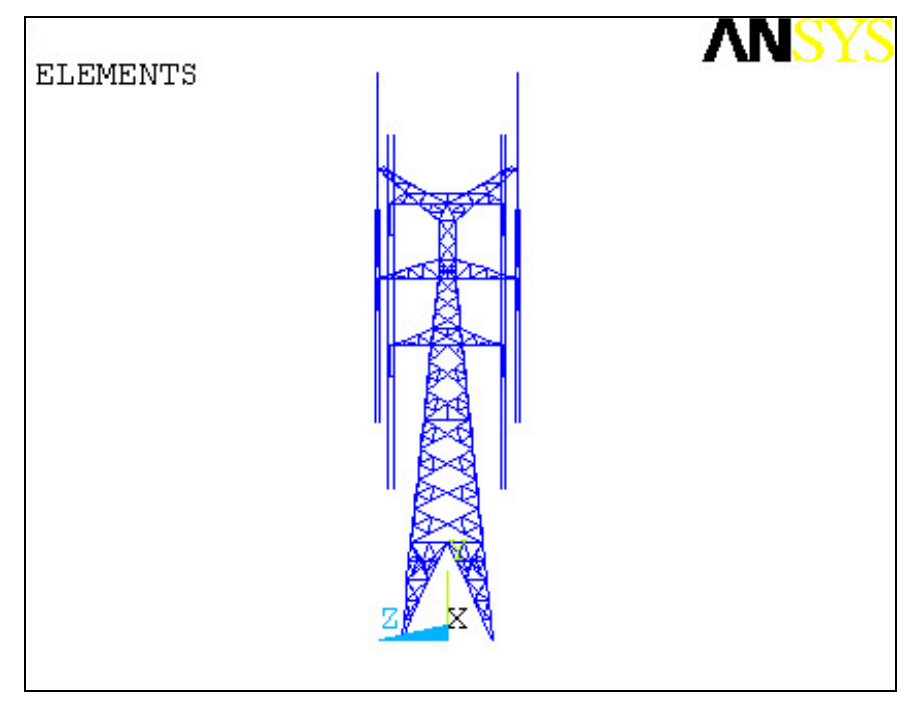

Fig. 3 The finite element model of tower and wire

Finite element model of the transmission line and tower. There was an interaction between the transmission tower and conductors, ground wires under loading state. So their models should be built together for simulating the loading conditions accurately. The analysis method proposed in the present investigation uses beam 188 finite elements to discrete all of members which are connected by rigid nodes. The adopted analysis strategy ignored specific structures at the place of joints, influence of jumper wires connection and height differences of suspension points of conductors. Only the connection mass was considered [5, 6]. Based on deformation and mechanical characteristics of transmission lines, the model was built by using rod finite elements LINK10 after form finding of lines $[7,8]$ was completed. And the effect of geometric nonlinearity was considered in finite element calculation. The transmission tower-line coupling model contained 7123 beam elements and 6337 nodes.

Specified load. In order to analyze the working conditions, the loads on the transmission tower can be divided into three parts: the first one is the weight of the transmission tower, the second one is the effects of the conductors (ground wires) on the transmission tower, and the third one is the effects of the additional force of settlement. Additional force of settlement was applied to the tower by changing supports' displacement. The value variation of root span was little and vertical settlement value of supports is listed in Table 1 . The common action of the three loads was considered as the load combinations. Based on the probability limit design theory and the requirement of the Code for design of 110-750kV overhead transmission line GB50545-2010 [9], transmission tower components were assessed according to the classification of stress property. 
Table 1 Vertical settlement value of supports

\begin{tabular}{cc}
\hline Tower leg & Heigh difference compared to leg A (m) \\
\hline A & 0 \\
B & -0.19 \\
C & -0.187 \\
D & -0.097 \\
\hline
\end{tabular}

\section{Calculation results and reinforcing scheme analysis}

Structure deformation and strength analysis. When the Tower 32\# is under the action of the uneven settlement, finite element analysis results show that the maximum value of displacement was $785 \mathrm{~mm}$. And it is situated in suspension points of ground wire on tower head, as illustrated in Fig. 4. The bars of tower are compression-bending/tension-bending members which are under the combination action of bending moment and axial force. Von Mises equivalent stress nephogram of the Fig. 5 shows that the stress value of Leg B is larger and the maximum stress value is 633MPa. This maximum stress is situated the root of tower leg, and it is larger than the yield strength of Q420.

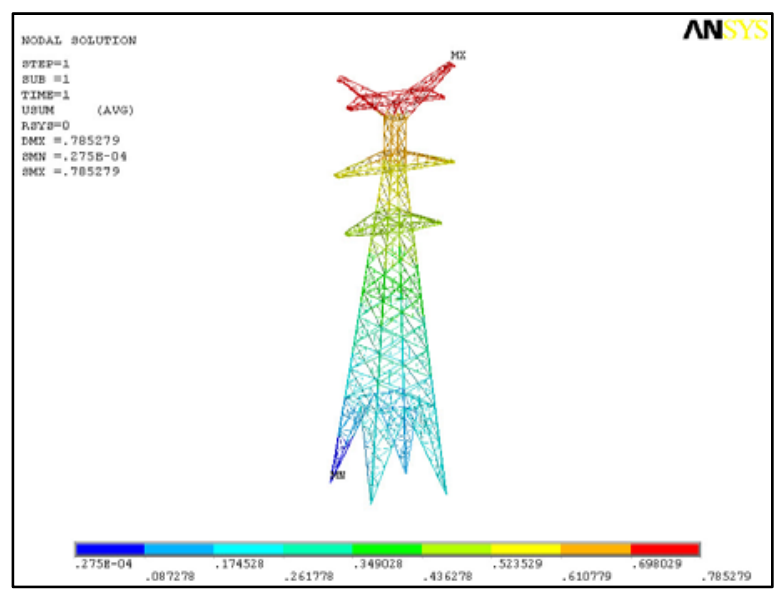

Fig. 4 The location of the maximum stress

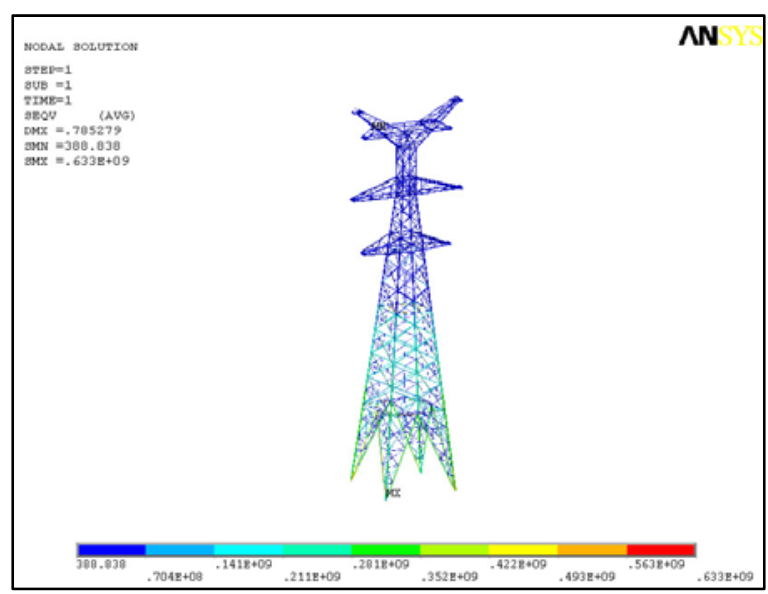

Fig. 5 The deformation of tower body

Reinforcing scheme analysis. After evaluating technical efficiency and economic cost and considering that long-term power outage was forbidden, one inclination rectification scheme was constituted. In the scheme, tower foundations were encased by steel plate $(400 \mathrm{~mm} \times 20 \mathrm{~mm})$, and they were connected together with each other by Q420 I-steel (Type 360×140×14/15.8). Strengthening the diaphragm in nine meters high place by Q420 U-steel were further measures, including the method of adding the new diaphragms in 1.8, 3.6, 5.4 and 7.2 meters high place. The new diaphragm was shown in Fig. 6. Fig. 7 showed the model of reinforcing scheme.

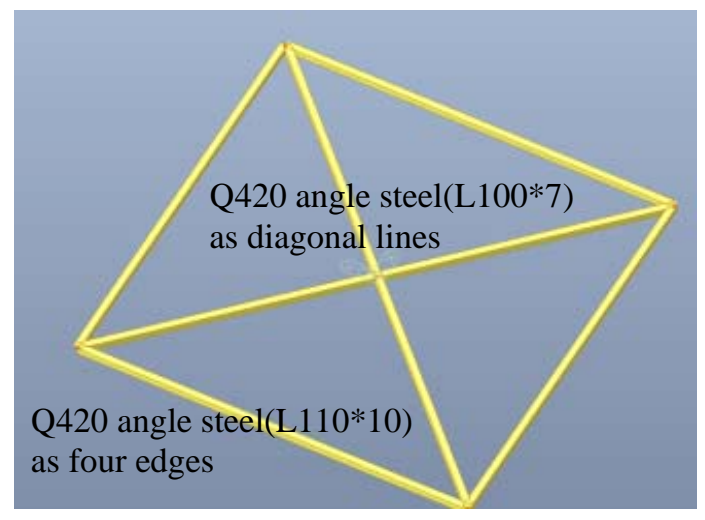

Fig. 6 The model of new diaphragms

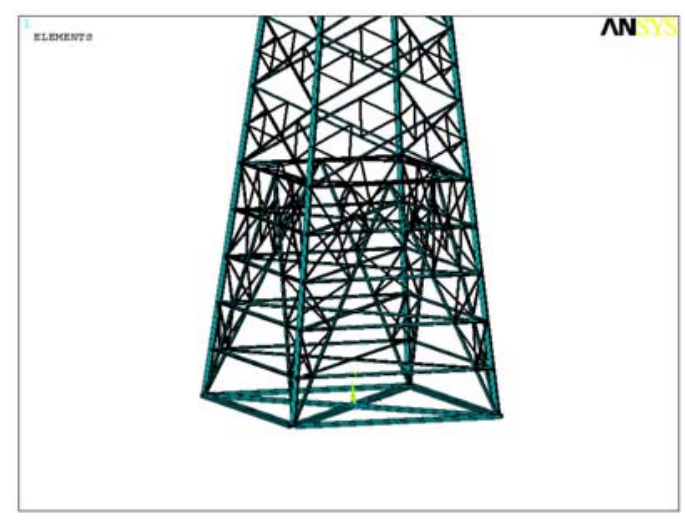

Fig. 7 The model of reinforcing scheme 
When the reinforced tower 32\# is under the action of the uneven settlement, finite element analysis results show that the maximum stress value is 199MPa. This maximum stress is situated the root of tower leg, and it is lower than the yield strength value of Q420 steel which meets the strength requirements.

\section{Conclusions}

This paper built the finite element model of transmission tower and lines and calculated structure internal force of transmission tower, and stress of truss members. Based on analyzing result, the reinforcing scheme was established and it achieved remarkable effectiveness. This paper indicates the following:

Finite element analysis results show that the stress value of Leg B is larger and the maximum stress value is 633MPa. This maximum stress is situated the root of tower leg, and it is larger than the yield strength of Q420. The bars of tower are compression-bending/tension-bending members which are under the combination action of bending moment and axial force.

Calculated maximum stress appears in the tower leg root, followed by the web members and the diaphragm at the bottom of tower. So these parts should be reinforced in the process of designing the towers at the area of goaf.

One inclination rectification scheme was constituted. The specific approaches were to encase tower foundations by steel plate and connect them by Q420 I-steel. Strengthening the diaphragm in nine meters high place by Q420 U-steel were further measures, including the method of adding the new diaphragms. Combined foundations were suggested to adopt instead of independent foundations for the transmission towers located in mine area, which could lower the risk of tower overturning.

\section{References}

[1] F.L. Yang, J.B. Yang, et al: Proceedings of the CSEE, Vol. 29 (2009) No.1, pp.100-106. (in Chinese)

[2] Q.R. Du: Wuhan Institute of Shipbuilding Technology, Vol. 5 (2006) No.3, pp.46-48. (in Chinese)

[3] Electric Power Construction Research Institute: Research Reports on Foundation of Transmission Line Tower in Mined-out Areas (State Grid Corporation of China, China 2006). (in Chinese)

[4] J.Q. Zhang, K. Yang, et al: Power System Technology, Vol. 30 (2006) No.2, pp.30-34. (in Chinese)

[5] Y.W. Feng: Steel Construction. Vol. 23 (2008), p. 21 (In Chinese)

[6] Q.H. Li, and J.B. Yang: Electric Power Construction. Vol. 27 (2006), p. 5 (In Chinese)

[7] M.J. Jian, D.Q. Zhang, and G.C. Zhang: Advanced Materials Research. Vol. 690-693 (2013), p. 1940-1944,

[8] X.H. Liu, H.J. Shi, and Y. Guo: Engineering Mechanics. Vol. 26 (2009), p. 244-249,

[9] Code for design of 110 750kV overhead transmission line. GB 50545-2010, 2010 (In Chinese) 